\title{
Teachers' Acceptance of Technologies for 4IR Adoption: Implementation of the UTAUT Model
}

\author{
Habibah Ab Jalil* \\ Innovative Learning Sciences Research Centre of Excellence (INNOVATE), \\ Faculty of Educational Studies, Universiti Putra Malaysia, Serdang, Malaysia \\ Manjula Rajakumar (D) and Zeinab Zaremohzzabieh \\ Universiti Putra Malaysia, Serdang, Malaysia
}

\begin{abstract}
Education departments all around the globe are working to increase the extent to which teachers adopt innovative technology, in order to scale up pedagogical innovation that uses new technologies. However, only a few studies have been done on the adoption and use of these tools for teaching by instructors in non-Western contexts. Therefore, the objective of this study was to examine teachers' behavior intention to adopt and use Industry 4.0 (IR4.0) technologies in Malaysia, in accordance with the unified theory of acceptance and the use of technology (UTAUT) model. A questionnaire was employed to acquire data from a randomly selected sample of 62 primary school teachers in Malaysia. The findings reveal that only two variables (namely, the facilitating conditions, and social influence variables) have a direct impact on the behavior intention of Malaysian primary school teachers to use IR4.0 technologies. Neither effort expectancy nor performance expectancy have an impact on the intention to use these technologies. The study concludes with a set of recommendations for improving policy and research on teachers' use of IR4 for education. This work demonstrates how the findings may assist primary school teachers to improve their understanding of 4IR adoption, and provides valuable suggestions for 4IR scholars, producers, and users.
\end{abstract}

Keywords: behavior intention, primary school teachers, fourth industrial revolution, Malaysia

\section{Introduction}

Technology plays a key role in education, as it can help students understand and retain concepts better. Technology stimulates curiosity in students' minds and transforms passive students into reactive, reactive-to-interactive, and aggressive agents (Owoseni et al., 2020; Raja \& Nagasubramani, 2018). Recent technological

* Corresponding author: Habibah Ab Jalil, habibahjali@@upm.edu.my 
developments have made modern technology particularly appealing for the school setting, and can readily be incorporated into classroom activities (Farella et al., 2020; Gómez-Trigueros, 2020). The capacity of these technologies to stimulate 'learning-by-making' experiences is a common aspect of these technologies (Ferguson et al., 2019). Furthermore, studies have found that using technologies has the potential to enhance education results through more innovative teaching and learning approaches (Chick et al., 2020). The fourth industrial revolution (4IR) will transform the future of education further (Ismail \& Hassan, 2019). 4IR refers to the current trend in industrial technology of computerization and exchanging data, such as cyber and physical systems, cloud computing, augmented and virtual reality (AR/VR), robotics, three-dimensional printing (3DP), and quantum computing (Butt, 2020). According to Kayembe and $\mathrm{Nel}$ (2019), these technologies make the process of teaching and learning simpler, in relative terms. Thus, it is critical to include 4IR technologies in teaching and learning, particularly for primary school students who must start preparing for the future workplace, which is always changing, and unexpected (see Henderson et al., 2017).

Education in the $21^{\text {st }}$ century is challenging, especially for primary school students, who are proficient users of technology even when they enrol at school for the first time (Zaremohzzabieh et al., 2016). Moreover, because conventional teaching methods are losing their functionality in $21^{\text {st }}$ century learning conditions, interactive learning is becoming more important, especially in the new norm caused by the COVID-19 pandemic, characterised by distance learning. Teachers must acquire skills in integrating 4IR, and they should be experts who are adaptable to new technologies and global issues (Lase, 2019; Tomczyk, 2020). However, as explained by Rumengan et al. (2018), it is the human component of the implementation cycle, not the technology, that will hinder progress in ensuring that the delivered technologies are used successfully. As a result, teachers, as key players in the education process, must accept new technologies and must gain confidence in incorporating them into lessons (Farjon et al., 2019). Furthermore, the effective application of the 4IR in education necessitates that teachers develop suitable skills to deploy, manage, and interact with new technologies (Butler-Adam, 2018).

Research studies have demonstrated that technology integration still poses a challenge to the majority of teachers. Researchers have investigated the determinants of teachers' attitudes towards the acceptance of technology-based education (Cha \& Kwon, 2018), but less extensive research has been done to verify instructors' use of IR4.0 technologies. Although the use of IR4.0 technologies is fast expanding, and their use in education has been broadly verified, not all school teachers are willing to employ these technologies (Farella et al., 2020). As stated by Razak et al. (2018), one of the main problems encountered by schools is teachers' unwillingness to accept modern teaching technologies. Different models of technology adoption exist, and some of them, such as the technology acceptance model (TAM), have been used to assess people's willingness to accept novel technologies (Elshafey et al., 2020). This research applied the unified theory of acceptance and use of technology (UTAUT) framework (Venkatesh et al., 2003), to examine teachers' intention of using 4IR technology tools for teaching and 
learning. As stated by Al-Mamary et al. (2018), it is one of the most broadly used models for predicting technology use in a variety of circumstances. The model suggests that teachers' intention to use technologies is determined by their performance expectancy, as well as facilitating conditions and social influence. Thus, the objective of this study was to determine how UTAUT model constructs affect teachers' adoption of IR4.0 technology.

\section{Theoretical Background and Hypothesis Testing}

To ensure the successful implementation of 4IR technologies by primary school teachers, acceptance and adoption are among the aspects that must be considered. 4IR technologies can be beneficial in schools, because they improve students' engagement with digital resources while they learn in real-world settings (Karakoyun \& Lindberg, 2020; Owoseni et al., 2020). Nowadays, the success of various methods of teaching and learning is highly dependent on teachers' acceptance of new tools and techniques (Scherer \& Teo, 2019).

Researchers have attempted to explain technology user acceptance based on theories of human behavior. Among these theories, the TAM, introduced by Davis (1985), has been a popular paradigm for studying aspects that influence users' adoption of technology. Using a complicated link between system characteristics (external factors) and potential system use, the TAM assumes that two variables - termed perceived ease of use and perceived usefulness - play a mediating function.

Academics (e.g., Sánchez-Prieto et al., 2016) mention that the TAM has some limitations. To address these limitations, Venkatesh et al. (2003) used the core items from a total of eight common technology acceptance models, including the TAM, and created a unified model, and called it the UTAUT model. This model adds significantly to research on technology acceptance and use, because of its capacity to combine multiple TAMs (Venkatesh et al., 2003). As a result, the UTAUT framework was used as the theoretical foundation in this study to evaluate the effects of technology-related variables on 4IR technology adoption. The model was used to investigate how different factors can promote teachers' behavioral (or behavior) intentions towards 4IR technologies in their teaching (see Figure 1).

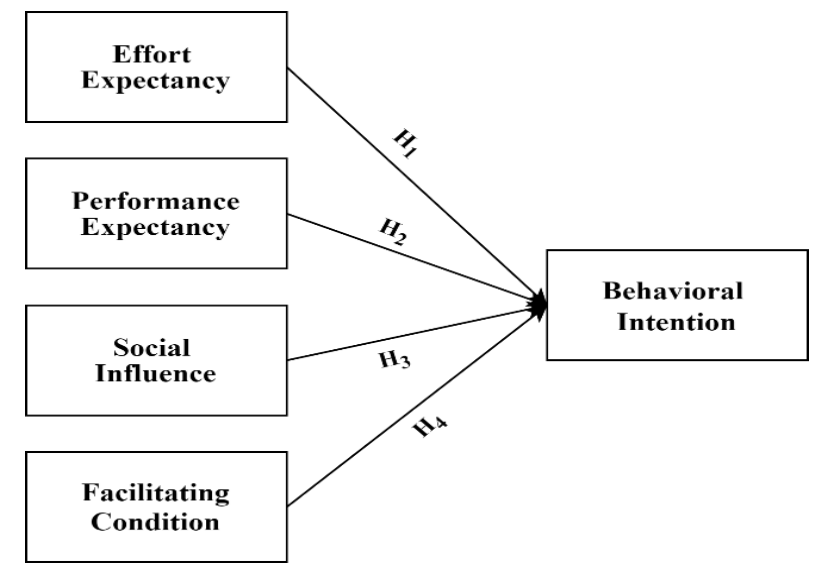

Figure 1. The research framework 


\subsection{Effort Expectancy and Teachers' Intention to Use 4IR Technology}

Effort expectancy is formally defined as the level of ease related to the use of technological tools (Venkatesh et al., 2012). As an important component of the UTAUT model, effort expectancy is mostly employed to assess users' intention to use technological tools (Venkatesh et al., 2003). Jang and Koh (2019) identified the role played by effort expectancy in identifying the acceptance of learning technologies. Information system researchers, such as Kaliisa et al. (2019), emphasize a relationship between effort expectancy and behavior intention in new, modern technologies. Other researchers who have employed the UTAUT model found that effort expectancy and behavior intention are linked (Oke \& Fernandes, 2020). As stated previously, effort expectancy has a positive influence on behavior intentions while using virtual reality (Shen et al., 2019). Consequently, Hypothesis 1 was proposed as follows:

Hypothesis 1: Effort expectancy is positively related to teachers' behavior intention to use 4IR technology.

\subsection{Performance Expectancy and Teachers' Intention to Use 4IR Technology} Performance expectancy can be defined as a person's belief that adopting technology will enhance job performance (Venkatesh et al., 2003). The UTAUT model commonly incorporates the performance expectancy concept that predicts behavior intention to use new technologies (Francisco \& Swanson, 2018). Sung et al. (2015), for instance, applied the UTAUT framework to investigate mobile learning in the South Korean context and conclude that it is significantly linked to behavior intention. The UTAUT model has been employed by several researchers, and evidence supports the notion that performance expectancy and the behavior intention to use technologies are linked (Almaiah \& Al Mulhem, 2019; Botero et al., 2018; Nikolopoulou, 2018). Studies have also shown the significant influence of performance expectancy on continuous intention to use mobile learning (AlEmran \& Granić, 2021). As a result, the following hypothesis was formulated:

Hypothesis 2: Performance expectancy is positively associated with teachers' behavior intentions to use 4IR technology.

\subsection{Social Influence and Teachers' Intention to Use 4IR Technology}

The UTAUT model factor of social influence is characterized as an individual's assessment of the importance of accepting a new technological tool, according to others (Venkatesh et al., 2003). Studies have investigated the role of social influence, which includes that of friends, family, co-workers, and peer influences, on individual behavior adoption (Shen et al., 2019), and conclude that it is a significant influencing factor for behavior intention (Lu et al., 2020). A study by Jain and Jain (2021) implies that, when teachers engage with others, they are more likely to have a strong behavior intention to use IR4.0 technologies for teaching. As a result, Hypothesis 3 suggests

Hypothesis 3: Social influence is positively linked to teachers' behavior intention to use 4IR technologies. 


\subsection{Facilitating Conditions and Teachers' Intentions to Use 4IR Technology}

A facilitating condition is an individual's confidence that an organizational and technological structure is in place to make system use easier (Venkatesh et al., 2003). In other words, facilitating conditions supply the external resources required to make a specific activity easier to complete (Ajzen, 1991). The availability of training and assistance are considered to be helpful circumstances in the context of workplace technology adoption. In the context of this study, facilitating conditions were assessed by teachers' perceptions of their ability to acquire the necessary resources and assistance to use IR4.0. Amadin et al. (2018) found that facilitating conditions have a positive influence on intentions to use technology. As a result, it was suggested that

Hypothesis 4: Facilitating conditions are positively related to teachers' behavior intention to use 4IR technologies.

\section{Methodology}

\subsection{Research Design}

A research design is an essential component of a study, and choosing the right design can help researchers obtain accurate results and, subsequently, achieve the aim of the study (Henson et al., 2020). As part of its hypothesis-generating research, the present study used a survey, and quantitative methodologies based on the positivist paradigm (Andrade, 2019).

\subsection{Participants and Data Collection Instruments}

A questionnaire was generated for the survey, which was developed and administered in both English and Malay. To evaluate the theoretical model, the questionnaire comprised two main sections: (1) respondent demographics, and (2) the model's construct measures.

All of the measuring items of the original UTAUT model were included and modified for use by this research. A five-point Likert scale was defined, from 1 (or strongly disagree) to 5 (or strongly agree).

Effort Expectancy: Effort expectancy means the level of easiness related while using technologies. Some of the original four items included perceived usability and difficulty (Venkatesh et al., 2003). The sample items are: I have found this technology easy to adopt, and My interaction with 3DP/AR/VR/Robotics technologies in teaching as well as learning would be simple to comprehend. A Cronbach's alpha value of 0.808 is reported for this scale.

Performance Expectancy (perceived usefulness): This measure was calculated using a four-item scale for perceived usefulness, job fit, extrinsic motivation, relative benefit, and technology predicted output, including 3DP, AR/VR, and robotics, in teaching and learning (Zhang et al., 2020). The sample item is Using 3DP/AR/VR/Robotics technologies for teaching and learning allow us to do responsibilities rapidly. The Cronbach's alpha value for this scale is 0.808 .

Social Influence: This measure was estimated using Venkatesh et al.'s (2003) fouritem scale. The following are examples of items: If my colleagues adopt it, I will 
include it into my teaching and learning, and The adoption of the technology was supported by the school. The Cronbach's alpha value for this scale is 0.867 .

Facilitating Conditions: Four items were measured under facilitating conditions (OECD, 2020; Venkatesh et al., 2003). The initial item is, I have the required resources to adopt 3DP/AR/VR/Robotics technologies in teaching and/or learning. The Cronbach's alpha value for this scale is 0.692 .

Behavior Intention: This component was measured with three items adopted from the studies of Venkatesh et al. (2003) and Rahi et al. (2018). The first item is, I aim to adopt 3DP/AR/VR/Robotics technologies during my teaching and/or learning during the next few months. The value of Cronbach's alpha for this scale is 0.857 .

The respondents in this research were teachers of science, design and technology, mathematics, and ICT who had been randomly selected from 74 primary schools from the Alor Gajah district of Malacca, Malaysia. Before collecting the data, four experts validated the face and content validity of the questionnaire. All the respondents provided informed consent before completing the questionnaire.

The researcher used the sample size criteria suggested by Ghauri et al. (2020), namely that the intention to do factor analysis means that answers numbering five to ten times more than the total number of items, must be gathered. As a result, the current study required a minimum of $95(19 \times 5)$ and a maximum of $190(19 \times 10)$ responses. The final sample consisted of 62 respondents, and had a response rate of $62.26 \%$.

Of the respondents who participated in the survey, 17 were men $(27.41 \%)$ and 45 were women $(72.58 \%$ ) (see Table 1$)$. The average age of the participants was 27.02 years $(\mathrm{SD}=8.34)$, and $22.6 \%$ reported having $11-15$ years of experience in the teaching field. A total of $27(43.5 .4 \%)$ of the schools at which respondents taught were located in urban areas, while $35(56.5 \%)$ were situated in rural areas.

Table 1. Demographic characteristics of respondents $(\mathrm{N}=62)$

\begin{tabular}{|c|c|c|c|c|c|c|}
\hline No. & Item & Type & Frequency & Percent & Mean & SD \\
\hline 1 & Age (in years) & & & & 27.02 & 8.34 \\
\hline & & $25-35$ & 15 & 24.19 & & \\
\hline & & $36-45$ & 28 & 45.16 & & \\
\hline & & $46-55$ & 18 & 29.03 & & \\
\hline & & $>56$ & 6 & 9.67 & & \\
\hline 2 & Gender & & & & & \\
\hline & & Male & 17 & 27.41 & & \\
\hline & & Female & 45 & 72.58 & & \\
\hline 3 & $\begin{array}{c}\text { Work experience } \\
\text { (years) }\end{array}$ & & & & & \\
\hline & & $\leq 5$ & 5 & 8.1 & & \\
\hline & & $6-10$ & 15 & 24.2 & & \\
\hline & & $11-15$ & 14 & 22.6 & & \\
\hline & & $16-20$ & 9 & 14.5 & & \\
\hline & & $21-25$ & 13 & 21 & & \\
\hline & & $26-30$ & 4 & 6.5 & & \\
\hline & & $31-35$ & 2 & 3.2 & & \\
\hline
\end{tabular}




\begin{tabular}{|l|l|l|l|l|l|l|}
\hline 4 & School location & & & & & \\
\hline & & Urban & 27 & 43.5 & & \\
\hline & & Rural & 35 & 56.5 & & \\
\hline
\end{tabular}

All the construct items exhibited significant composite reliability, as well as acceptable levels of reliability ( $\alpha$ ), according to the reliability test. This means that teachers had made significant changes from performance expectancy to performance expectancy, which had a loading of less than 0.5. If the average variance extracted (AVE) is below standard level, the lowest loading can be removed (Henseler et al. (2015). Thus, performance expectancy Item PE4 was discarded. The Cronbach's alpha value for each scale ranged from 0.652 to 0.902, which represents acceptable reliability for each construct (see Table 2). The average variance extracted scores, which were between 0.589 and 0.836 , imply that all five constructs have good convergency (Hair et al., 2020).

\section{Data Analysis and Results}

PLS-SEM approach and SmartPLS 3.3.3 software were used to analyze the data, based on Hair et al.'s (2017) recommendation for studies with small to medium sample sizes. Kock et al.'s (2019) two-step method was used to assess the data that had been gathered. First, the study investigated the measurement model's reliability, as well as the convergent and the discriminant validity. The structural model was, then, assessed to determine the direction and power of the connections between the theoretical components.

\subsection{Measurement Model}

The reliability and validity of the constructs were validated, and the measurement model was examined for reflecting indicators. The various latent constructs were subjected to factor analysis (Hair et al., 2017). The reliability of the composite variables varied from 0.692 to 0.902 , which is deemed satisfactory (Hair et al., 2017).

Convergent validity was used to establish the validity of the model. First, the data revealed that factor loading values were above 0.70 . This means that the items of each construct have adequate convergent validity. The AVE was above 0.50, composite reliability (CR) was 0.70 , as shown in Table 2 .

Table 2. Construct reliability and validity measures

\begin{tabular}{|c|c|c|c|c|c|c|}
\hline Constructs & Item No. & Loading & a & rho_A & CR & AVE \\
\hline Effort Expectancy & 1 & 0.73 & 0.808 & 0.831 & 0.874 & 0.635 \\
\hline & 2 & 0.79 & & & & \\
\hline & 3 & 0.87 & & & & \\
\hline & 4 & 0.77 & & & & \\
\hline & 1 & & & & & \\
\hline $\begin{array}{c}\text { Performance } \\
\text { Expectancy }\end{array}$ & 2 & 0.88 & 0.902 & 0.916 & 0.939 & 0.836 \\
\hline & 3 & 0.93 & & & & \\
\hline & 1 & 0.81 & 0.867 & 0.872 & 0.91 & 0.734 \\
\hline Social Influence & 2 & 0.92 & & & & \\
\hline & & & & & & \\
\hline
\end{tabular}




\begin{tabular}{|c|c|c|c|c|c|c|}
\hline & 3 & 0.86 & & & & \\
\hline & 4 & 0.78 & & & & \\
\hline $\begin{array}{l}\text { Facilitating } \\
\text { Conditions }\end{array}$ & 1 & 0.74 & 0.692 & 0.654 & 0.811 & 0.589 \\
\hline & 2 & 0.78 & & & & \\
\hline & 3 & 0.77 & & & & \\
\hline $\begin{array}{c}\text { Behavior } \\
\text { Intention }\end{array}$ & 1 & 0.82 & 0.857 & 0.859 & 0.913 & 0.779 \\
\hline & 2 & 0.90 & & & & \\
\hline & 3 & 0.91 & & & & \\
\hline
\end{tabular}

Discriminant validity measures the degree to which one construct differs from another, using empirical standards. This study combined Fornell and Larcker's criteria with the heterotrait-monotrait (or HTMT) ratios of relations, to integrate multiple approaches (Henseler et al., 2015). We found that discriminant validity was attained, due to the square root of the AVE of every construct being greater than the correlation values of any construct pairs, according to the FornellLarcker criteria. In addition, as indicated in Table 3, the standards of HTMT were all below the 0.85 cutoff value. As a result, this study reveals that effort expectancy, facilitating conditions, social influence, performance expectancy, and behavior intention could all be differentiated.

Table 3. The Measurement model and discriminant validity

\begin{tabular}{|l|c|c|c|c|c|c|c|c|c|c|}
\hline \multirow{2}{*}{ Constructs } & \multicolumn{4}{|c|}{ Fornell-Larcker } & \multicolumn{5}{c|}{ Heterotrait-Monotrait } \\
\cline { 2 - 11 } & $\mathbf{1}$ & $\mathbf{2}$ & $\mathbf{3}$ & $\mathbf{4}$ & $\mathbf{5}$ & $\mathbf{1}$ & $\mathbf{2}$ & $\mathbf{3}$ & $\mathbf{4}$ & $\mathbf{5}$ \\
\hline $\begin{array}{l}\text { 1. Behavior } \\
\text { Intention }\end{array}$ & 0.883 & & & & & & & & & \\
\hline $\begin{array}{l}\text { 2. Effort } \\
\text { Expectancy }\end{array}$ & 0.66 & 0.797 & & & & 0.783 & & & & \\
\hline $\begin{array}{l}\text { 3. Facilitating } \\
\text { Conditions }\end{array}$ & 0.604 & 0.604 & 0.768 & & & 0.807 & 0.813 & & & \\
\hline $\begin{array}{l}\text { 4. Performance } \\
\text { Expectancy }\end{array}$ & 0.448 & 0.554 & 0.306 & 0.914 & & 0.505 & 0.645 & 0.399 & & \\
\hline 5. Social Influence & 0.669 & 0.814 & 0.517 & 0.568 & 0.846 & 0.766 & 0.575 & 0.671 & 0.64 & \\
\hline
\end{tabular}

\subsection{Structural Model}

Once the measurement model evaluation had been performed, and reliability and validity had been determined, the structural relationships were created. Exogenous variables explained $52.6 \%$ of the variance in behavior intention, which indicates moderate predictive ability (See Figure 2). The bootstrapping approach was then used to assess the significance of the connections among the variables (see Table 3). The bootstrap process involved a resampling of the subsample of 5,000 occurrences, which are equivalent to the validated results, to determine the significance of path estimations. It was computed using a 5\% two-tail significance. The findings indicate that there is no association between teachers' effort expectancy and behavior intentions $(\beta=0.154, \mathrm{t}=1.371, \mathrm{p}<0.001)$. Thus, Hypothesis 1 is rejected. The findings confirm the results of other studies, such as that of Bardakc1 and Alkan (2019), that effort expectancy is not a good predictor of teachers' behavior intention. $\mathrm{H}_{2}$ is rejected too, as the result demonstrates that there is no significant relationship between performance expectancy and behavior intention $(\beta=0.073, \mathrm{t}=0.77, \mathrm{p}<0.001)$. This finding contrasts with that of other studies, such as that of Harmandaoğlu Baz et al. (2019), which found that 
performance expectancy is generally a predictor of teachers' behavior intention to use novel technologies. The present findings suggest a significant influence by social influence on teachers' behavior intention $(\beta=0.340, \mathrm{t}=2.412, \mathrm{p}=0.05), \mathrm{H}_{3}$ is, therefore, supported. This finding is in line with that of studies that report a meaningful association between social influence and behavior intentions of teachers to use new technologies (e.g., Yilmaz \& Baydas, 2016). Moreover, the findings acquired from the path coefficient indicate that the facilitating conditions factor $(\beta=0.313, \mathrm{t}=2.939, \mathrm{p}<0.001)$ is significantly related to behavior intention, thus, $\mathrm{H}_{4}$ is supported. Our findings are in line with that of Nikou and Economides (2019), which demonstrates that facilitating conditions improve the intentions of STEM teachers to adopt modern devices. The independent variables explain $61.7 \%$ of the variance in behavioral intention.

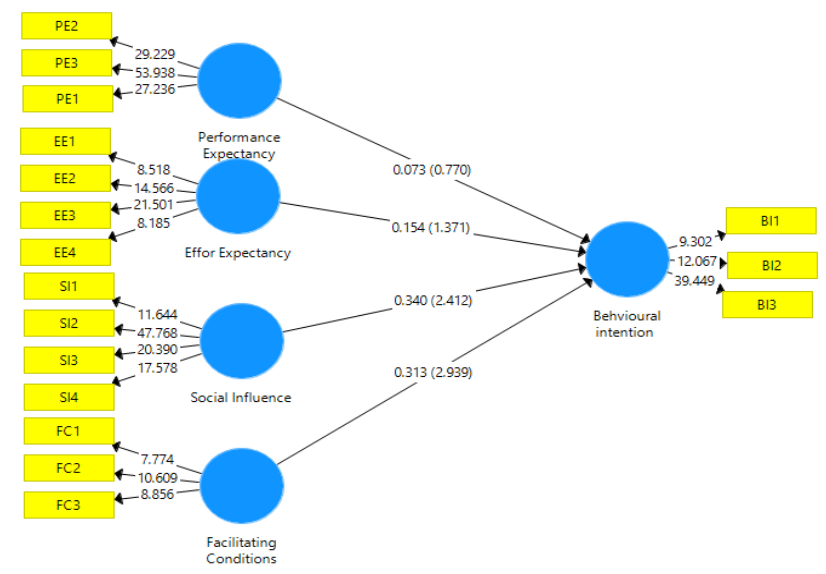

Figure 2. Structural model

Table 4. The output of structural model

\begin{tabular}{|c|c|c|c|c|c|c|c|c|}
\hline \multirow{2}{*}{ Hypothesis } & \multirow{2}{*}{ Path } & \multirow{2}{*}{$\mathrm{M}$} & $\mathrm{SD}$ & \multirow{2}{*}{$\mathrm{t}$} & $\mathrm{P}$ & \multicolumn{2}{|c|}{$\mathrm{BCB}(95 \% \mathrm{CI})$} & \multirow{2}{*}{ Decision } \\
\cline { 1 - 4 } & & & & & & $\mathrm{LB}$ & $\mathrm{UB}$ & \\
\hline Hypothesis 1 & $\mathrm{EE} \rightarrow \mathrm{BI}$ & 0.155 & 0.112 & 1.371 & 0.171 & -0.05 & 0.38 & Rejected \\
\hline Hypothesis 2 & $\mathrm{FC} \rightarrow \mathrm{BI}$ & 0.328 & 0.107 & 2.939 & $\begin{array}{c}0.003 \\
* * *\end{array}$ & 0.091 & 0.512 & Accepted \\
\hline Hypothesis 3 & $\mathrm{PE} \rightarrow \mathrm{BI}$ & 0.075 & 0.095 & 0.77 & 0.442 & -0.148 & 0.243 & Rejected \\
\hline Hypothesis 4 & $\mathrm{SI} \rightarrow \mathrm{BI}$ & 0.332 & 0.141 & 2.412 & $\begin{array}{c}0.016 \\
* *\end{array}$ & 0.074 & 0.604 & Accepted \\
\hline
\end{tabular}

Note EE-Effort Expectancy; BI-Behavior Intention; FC-Facilitating Condition; PE=4; Performance Expectancy; SISocial Influence; ${ }^{* *} \mathrm{R}^{2}(\mathrm{BI})=0.526 ;{ }^{* * *} \mathrm{P}<0.001 ;{ }^{* *} \mathrm{P}<0.05$

Finally, the risks of collinearity were ruled out by the variance inflation factor (VIF) values being below 5 (see Table 5).

Table 5. Structural model collinearity (inner VIFs)

\begin{tabular}{|l|c|c|c|c|c|}
\hline \multicolumn{1}{|c|}{ Construct } & 1 & 2 & 3 & 4 & 5 \\
\hline 1. Behavior Intention & & 1.386 & 1.203 & 1.284 & 1.001 \\
\hline 2. Effort Expectancy & & & & & \\
\hline 3. Facilitating Condition & & 1.000 & & & \\
\hline 4. Performance Expectancy & & & & & 1.006 \\
\hline 5. Social Influence & & & & 1.000 & \\
\hline
\end{tabular}


The structural model's predictive significance was also assessed using $\mathrm{Q}^{2}$ value, in addition to $\mathrm{R}^{2}$ and $\mathrm{f}^{2}$. According to the rule, the structural model has a predictive value if the $\mathrm{Q}^{2}$ value for a particular reflective endogenous latent variable is higher than 0 - otherwise, the model has no predictive value (Hair et al., 2017). The blindfolding findings show that behavior intention (0.39), effort expectancy (0.068), facilitating conditions (0.09), performance expectancy (0.048), and social influence (0.081) are all predictively significant (Henseler et al., 2015). With the standardized root-mean-square residual score at 0.06 - significantly below the 0.10 criterion - the study, thus, validates the overall fit of the structural model (Henseler et al., 2015) (Table 6).

Table 6. Predictive relevance of the structural model

\begin{tabular}{|c|c|c|c|c|}
\hline No. & Construct & SSO & SSE & $\mathrm{Q}^{2}(=1-$ SSE/SSO) \\
\hline 1 & Behavior Intention & 225 & 137.282 & 0.39 \\
\hline 2 & Effort Expectancy & 300 & 300 & 0.068 \\
\hline 3 & Facilitating Condition & 225 & 225 & 0.09 \\
\hline 4 & Performance Expectancy & 225 & 225 & 0.048 \\
\hline 5 & Social Influence & 300 & 300 & 0.081 \\
\hline
\end{tabular}

\section{Discussion}

This work aimed to determine the factors that impact the behavior intentions of primary school teachers to use 4IR technologies in education. The findings concerning the UTAUT model variables reveal that effort expectation has no significant beneficial influence on behavior intention related to using 4IR technologies. The results contradict the initial hypothesis of the UTAUT model (Venkatesh et al., 2003). Teachers' willingness to adopt new technology tools for teaching increases when they believe the technologies are user-friendly, straightforward, and easy to use. The study also discovered that facilitating conditions have a significant and positive impact on the behavior intentions to use 4IR technologies. This finding confirms the initial hypothesis of the UTAUT model, and also supports the findings of Kung-Teck et al. (2019), which state that facilitating conditions predict teacher intentions to use cutting-edge technologies. It can be said that factors such as time and fiscal and technological resources can increase teachers' intention to use technologies such as 3DP, AR/VR and robotics for teaching purposes. Concerning performance expectancy, the present findings contradict the original UTAUT model (Chao, 2019). This finding indicates that performance expectancy does not have a significant and positive impact on the behavioral intentions of teachers. In addition, it is inconsistent with other studies, which report that teachers believe that using new technologies will help them to improve students' performance (Ibili et al., 2019). In this study, the impact of social influence on behavior intention to adopt IR4.0 technologies was significant. This result corresponds with the original theoretical foundation of the UTAUT model (Venkatesh et al., 2003), in which social influence is a key factor in the model. This finding can be explained by the relatively strong influence close colleagues and acquaintances have in education settings. In addition, Zhao et al. (2021) found that the collectivist cultures of Asian countries mean others' ideas are salient for the decision to adopt new technologies. According to Zhang et al. (2018), variations in technology adoption are associated with cultural factors. 
Individualistic cultures focus on straight and formal sources for knowledge, while individuals from collectivist cultures, such as those in Southeast Asia, rely more on subjective innovation evaluations that are conveyed by like-minded individuals who have already accepted the innovation (Zhao et al., 2021).

\section{Conclusion and Recommendations}

The theoretical foundation of the UTUAT model was used by this study to examine teachers' intentions to adopt 4IR technologies for teaching and learning. As theorized, facilitating conditions and social influence were found to affect teachers' intentions to use IR4.0. However, no statistically significant pathways connect the other two variables (i.e. effort expectancy and performance expectancy) with behavior intention. The results provide a significant contribution to the current work on IR4.0 acceptance. This is one of the first studies to consider the context of schools, namely that, owing to limited resources, they face particular problems in maximizing teachers' ability to apply IR4 technologies. Furthermore, the study of IR4 acceptance requires a well-established model that includes the characteristics that can predict IR4 acceptance by school teachers. This research is significant because it was the first application of the UTAUT model to investigate teachers' intentions to use IR4.0 for teaching. These findings can assist IR4.0 researchers and developers to create better educational experiences.

Different factors should be incorporated in future versions of the model, to improve understanding of teachers' intentions to accept and use IR4.0 technologies for education, and these constructs should be fully explored by future studies. Furthermore, studies on how teachers can use IR4.0 technologies in teaching, how to distribute educational content simply and instantly on all devices by school teachers, and how to encourage students to engage in collaborative learning, would also be useful. Additionally, providing teachers with analytical data that allow them to monitor their students' progress will improve the likelihood of IR4.0 teaching tools being used in the future. Finally, the findings of this study may be useful to future research on the use of IR4.0based teaching aids in education. Future academics, educational IR4.0 technology developers, instructors, and curriculum designers could benefit from these findings.

\section{Study Limitations}

The results of this investigation were limited by several issues. The study focused on some of the elements that influence teachers' acceptance of 4IR technology. An inability to generalize the study conclusions is one disadvantage of the current analysis. Only small groups of teachers took part in this study, and teachers were asked to complete questionnaires. The chosen respondents may not be representative of, and their inputs may not be generalizable to the overall sample population. Furthermore, the study's findings cannot be applied to other individuals or school personnel. While this study, through validity and reliability testing, established a fair testing instrument and measuring scales, the study's internal validity may require further attention, as a consequence of how the respondents completed the questionnaires. The study, like any other, used a self- 
administered questionnaire, which implies that respondents may have given superficial responses. Moreover, this situation may have been exacerbated by some respondents providing information that they believed would impress the researchers. To remedy this limitation, future research should employ a new approach to investigations, such as a longitudinal study. A different quantitative or qualitative technique may provide additional insight into the analysis.

\section{References}

Ajzen, I. (1991). The theory of planned behavior. Organizational Behavior and Human Decision Processes, 50(2), 179-211.

Al-Emran, M., \& Granić, A. (2021). Is it still valid or outdated? A bibliometric analysis of the technology acceptance model and its applications from 2010 to 2020. In M. AlEmran \& K. Shaalan (Eds.), Recent advances in technology acceptance models and theories (Vol. 335, pp. 1-12). Springer. https:// doi.org/10.1007/978-3-030-649876_1

Almaiah, M. A., \& Al Mulhem, A. (2019). Analysis of the essential factors affecting of intention to use of mobile learning applications: A comparison between universities adopters and non-adopters. Education and Information Technologies, 24(2), 1433-1468.

Al-Mamary, Y., Al-nashmi, M., Shamsuddin, A., \& Hassan, Y. A. G. (2018). Development of an Integrated Model for Successful Adoption of Management Information Systems in Organizations. Progress in Machines and Systems, 7(1), 1-27.

Amadin, F. I., Obienu, A. C., \& Osaseri, R. O. (2018). Main barriers and possible enablers of Google apps for education adoption among university staff members. Nigerian Journal of Technology, 37(2), 432-439.

Andrade, C. (2019). Describing research design. Indian Journal of Psychological Medicine, 41(2), 201-202.

Bardakc1, S., \& Alkan, M. F. (2019). Investigation of Turkish preservice teachers' intentions to use IWB in terms of technological and pedagogical aspects. Education and Information Technologies, 24(5), 2887-2907.

Botero, G. G., Questier, F., Cincinnato, S., He, T., \& Zhu, C. (2018). Acceptance and usage of mobile assisted language learning by higher education students. Journal of Computing in Higher Education, 30(3), 426-451.

Butler-Adam, J. (2018). The fourth industrial revolution and education. South African Journal of Science, 114(5-6), 1-1. https://doi.org/10.17159/sajs.2018/a0271

Butt, J. (2020). A strategic roadmap for the manufacturing industry to implement industry 4.0. Designs, 4(2), 1-31.

Cha, K., \& Kwon, S. (2018). Understanding the adoption of e-learning in South Korea: Using the extended Technology Acceptance Model approach. KEDI Journal of Educational Policy, 15(2).

Chao, C.-M. (2019). Factors Determining the Behavioral Intention to Use Mobile Learning: An Application and Extension of the UTAUT Model. Frontiers in Psychology, 10, $1-14$.

Chick, R. C., Clifton, G. T., Peace, K. M., Propper, B. W., Hale, D. F., Alseidi, A. A., \& Vreeland, T. J. (2020). Using technology to maintain the education of residents during the COVID-19 pandemic. Journal of Surgical Education, 77(4), 729-732. https://doi.org/10.1016/j.jsurg.2020.03.018

Davis, F. D. (1985). A technology acceptance model for empirically testing new end-user information systems: Theory and results [PhD Thesis]. Massachusetts Institute of Technology. 
Elshafey, A., Saar, C. C., Aminudin, E. B., Gheisari, M., \& Usmani, A. (2020). Technology acceptance model for Augmented Reality and Building Information Modeling integration in the construction industry. Journal of Information Technology in Construction, 25, 161-172. https://doi.org/10.36680/j.itcon.2020.010

Farella, M., Arrigo, M., Taibi, D., Todaro, G., Chiazzese, G., \& Fulantelli, G. (2020). ARLectio: An Augmented Reality Platform to Support Teachers in Producing Educational Resources. Proceedings of the 12th International Conference on Computer Supported Education (CSEDU 2020), 2, 469-475. https://doi.org/10.5220/0009579104690475

Farjon, D., Smits, A., \& Voogt, J. (2019). Technology integration of pre-service teachers explained by attitudes and beliefs, competency, access, and experience. Computers E Education, 130, 81-93. https://doi.org/10.1016/j.compedu.2018.11.010

Ferguson, R., Coughlan, T., Egelandsdal, K., Gaved, M., Herodotou, C., Hillaire, G., Jones, D., Jowers, I., Kukulska-Hulme, A., Mcandrew, P., Misiejuk, K., Ness, J., Rienties, B., Scanlon, E., Sharples, M., Wasson, B., Welle, M., \& Whitelock, D. (2019). Innovating Pedagogy 2019 (No. 7). The Open University.

Francisco, K., \& Swanson, D. (2018). The supply chain has no clothes: Technology adoption of blockchain for supply chain transparency. Logistics, 2(1), 1-13. https:// doi.org/10.3390/logistics2010002

Ghauri, P., Grønhaug, K., \& Strange, R. (2020). Research methods in business studies. Cambridge University Press.

Gómez-Trigueros, I. (2020). Digital teaching competence and space competence with TPACK in social sciences. International Journal of Emerging Technologies in Learning (IJET), 15(19), 37-52.

Hair, J. F., Hult, G. T. M., Ringle, C. M., \& Sarstedt, M. (2017). A primer on partial least squares structural equation modeling (PLS-SEM) (2nd ed.). Sage.

Harmandaoğlu Baz, E., Cephe, P. T., \& Balcıkanlı, C. (2019). Understanding EFL preservice teachers' behavioral intentions to use cloud applications. E-Learning and Digital Media, 16(3), 221-238.

Henderson, M., Selwyn, N., \& Aston, R. (2017). What works and why? Student perceptions of 'useful' digital technology in university teaching and learning. Studies in Higher Education, 42(8), 1567-1579. https:/ / doi.org/10.1080/03075079.2015.1007946

Henseler, J., Ringle, C. M., \& Sarstedt, M. (2015). A new criterion for assessing discriminant validity in variance-based structural equation modeling. Journal of the Academy of Marketing Science, 43(1), 115-135.

Henson, R., Stewart, G., \& Bedford, L. (2020). Key challenges and some guidance on using strong quantitative methodology in education research. Journal of Urban Mathematics Education, 13(2), 42-59. https:// doi.org/10.21423/jume-v13i2a382

Ibili, E., Resnyansky, D., \& Billinghurst, M. (2019). Applying the technology acceptance model to understand maths teachers' perceptions towards an augmented reality tutoring system. Education and Information Technologies, 24, 2653-2675. https://doi.org/10.1007/s10639-019-09925-z

Ismail, A. A., \& Hassan, R. (2019). Technical competencies in digital technology towards industrial revolution 4.0. Journal of Technical Education and Training, 11(3), 55-62.

Jang, H., \& Koh, J. (2019). The Influence of the Perceived Value of the Elderly on the Intention of Smart Device Internet Usage: A Lifelong Learning Perspective for the Elderly. Journal of Practical Engineering Education, 11(1), 87-103.

Kaliisa, R., Palmer, E., \& Miller, J. (2019). Mobile learning in higher education: A comparative analysis of developed and developing country contexts. British Journal of Educational Technology, 50(2), 546-561. 
Karakoyun, F., \& Lindberg, O. J. (2020). Preservice teachers' views about the twenty-first century skills: A qualitative survey study in Turkey and Sweden. Education and Information Technologies, 25(4), 2353-2369. https://doi.org/10.1007/s10639-02010148-W

Kayembe, C., \& Nel, D. (2019). Challenges and opportunities for education in the Fourth Industrial Revolution. African Journal of Public Affairs, 11(3), 79-94.

Kock, F., Josiassen, A., \& Assaf, A. G. (2019). Scale development in tourism research: Advocating for a new paradigm. Journal of Travel Research, 58(7), 1227-1229.

Kung-Teck, W., Yeop, M. A., \& Muhammad, M. M. (2019). Modelling the Factor Influencing the Implementation of Mobile-Heutagogical Practices among Teachers: An Application of Invariance Multi-Group Structural Model. International Journal of Learning, Teaching and Educational Research, 18(12), 1-16. https:// doi.org/10.26803/ijlter.18.12.1

Lase, D. (2019). Pendidikan di era revolusi industri 4.0 [Education in the era of industrial revolution 4.0]. SUNDERMANN: Jurnal Ilmiah Teologi, Pendidikan, Sains, Humaniora Dan Kebudayaan, 12(2), 28-43. https:// doi.org/0000-0002-1609-182X

Lu, L., Yuan, Y., Chen, X., \& Li, Z. (2020). A hybrid recommendation method integrating the social trust network and local social influence of users. Electronics, 9(9), 1-27.

Nikolopoulou, K. (2018). Mobile learning usage and acceptance: Perceptions of secondary school students. Journal of Computers in Education, 5(4), 499-519.

Nikou, S. A., \& Economides, A. A. (2019). Factors that influence behavioral intention to use mobile-based assessment: A STEM teachers' perspective. British Journal of Educational Technology, 50(2), 587-600.

OECD. (2020). Digital strategies in education across OECD countries: Exploring education policies on digital technologies (Working Paper No. 226; OECD Education). OECD.

Oke, A., \& Fernandes, F. A. P. (2020). Innovations in teaching and learning: Exploring the perceptions of the education sector on the 4 th industrial revolution (4IR). Journal of Open Innovation: Technology, Market, and Complexity, 6(2), 1-22.

Owoseni, A., Ibem, E., \& Opoko, A. (2020). Socio-Economic Profiling of Students and its Impact on Learning Outcomes. International Journal of Emerging Technologies in Learning (IJET), 15(19), 213-222.

Rahi, S., Ghani, M., \& Ngah, A. (2018). A structural equation model for evaluating user's intention to adopt internet banking and intention to recommend technology. Accounting, 4(4), 139-152.

Raja, R., \& Nagasubramani, P. C. (2018). Impact of modern technology in education. Journal of Applied and Advanced Research, 3(1), 33-35.

Razak, N. A., Jalil, H. A., Krauss, S. E., \& Ahmad, N. A. (2018). Successful implementation of information and communication technology integration in Malaysian public schools: An activity systems analysis approach. Studies in Educational Evaluation, 58, 17-29. https://doi.org/10.1016/j.stueduc.2018.05.003

Rumengan, A. E., Rumengan, J., Wibisono, C., \& Otok, B. W. (2018). Structural Equation Modeling in Business Performance Through Competitive Advantage With Information Technology As Moderating. International Journal of Mechanical Engineering and Technology (IJMET), 9(10), 632-644.

Sánchez-Prieto, J. C., Olmos-Migueláñez, S., \& García-Peñalvo, F. J. (2016). Informal tools in formal contexts: Development of a model to assess the acceptance of mobile technologies among teachers. Computers in Human Behavior, 55, 519-528. https://doi.org/10.1016/j.chb.2015.07.002

Scherer, R., \& Teo, T. (2019). Unpacking teachers' intentions to integrate technology: A meta-analysis. Educational Research Review, 27, 90-109. https:// doi.org/10.1016/j.edurev.2019.03.001 
Shen, C., Ho, J., Ly, P. T. M., \& Kuo, T. (2019). Behavioural intentions of using virtual reality in learning: Perspectives of acceptance of information technology and learning style. Virtual Reality, 23(3), 313-324.

Sung, H.-N., Jeong, D.-Y., Jeong, Y.-S., \& Shin, J.-I. (2015). The relationship among selfefficacy, social influence, performance expectancy, effort expectancy, and behavioral intention in mobile learning service. International Journal of U-and eService, Science and Technology, 8(9), 197-206.

Tomczyk, L. (2020). Attitude to ICT and Self-Evaluation of Fluency in Using New Digital Devices, Websites and Software among Pre-Service Teachers. International Journal of Emerging Technologies in Learning (IJET), 15(19), 200-212.

Venkatesh, V., Morris, M. G., Davis, G. B., \& Davis, F. D. (2003). User acceptance of information technology: Toward a unified view. MIS Quarterly, 27(3), 425-478.

Venkatesh, V., Thong, J. Y., \& Xu, X. (2012). Consumer acceptance and use of information technology: Extending the unified theory of acceptance and use of technology. MIS Quarterly, 36(1), 157-178.

Yilmaz, R. M., \& Baydas, O. (2016). Pre-service teachers' behavioral intention to make educational animated movies and their experiences. Computers in Human Behavior, $63,41-49$.

Zaremohzzabieh, Z., Ahrari, S., Samah, B. A., \& Othman, J. B. (2016). Youth and Mobile: An Investigation of Socialization. In Handbook of Research on Human Social Interaction in the Age of Mobile Devices (pp. 429-451). IGI Global.

Zhang, Y., Weng, Q., \& Zhu, N. (2018). The relationships between electronic banking adoption and its antecedents: A meta-analytic study of the role of national culture. International Journal of Information Management, 40, 76-87. https://doi.org/10.1016/j.ijinfomgt.2018.01.015

Zhang, Z., Cao, T., Shu, J., \& Liu, H. (2020). Identifying key factors affecting college students' adoption of the e-learning system in mandatory blended learning environments. Interactive Learning Environments, 1-14.

Zhao, Y., Wang, N., Li, Y., Zhou, R., \& Li, S. (2021). Do cultural differences affect users'elearning adoption? A meta-analysis. British Journal of Educational Technology, 52(1), 20-41. 